Федоринов В. А. Федоринов М. В. Кулик А. Н. Kox A. K.

\title{
ЭЛЕКТРОКОНТАКТНЫЙ ПРОВОД И СПОСОБЫ ЕГО ИЗГОТОВЛЕНИЯ
}

Электроконтактный провод служит для передачи электрической энергии подвижному составу железных дорог и электрофицированному муниципальному транспорту. Провод изготавливают из материалов с высокой электропроводностью, к которым относятся медь и алюминий. В отечественной практике для изготовления контактного провода, ввиду более высокой износостойкости, преимущественно используют медь и ее сплавы.

Стандартом [1] на контактные провода из меди и ее сплавов предусмотрен выпуск контактных проводов, различных по форме и площади поперечного сечения, в том числе круглых. Основной трудностью производства таких проводов является обеспечение изготовления изделий большой строительной длины, которая в зависимости от сечения провода находится в пределах от 1400 до 5500 метров. Для наиболее востребованных типоразмеров провода масса бухты должна составлять не менее 1500 кг.

Протяженность трамвайных (один провод) и троллейбусных (два провода) линий Украины более 10 тыс. км. Протяженность контактных сетей железных дорог Украины - более 8500 км, а с учетом наличия двух полотен - более 17000 км. Протяженность в Донбассе только трамвайно-троллейбусных линий более 1600 км, а с учетом наличия двух проводов на троллейбусных линиях - более 2600 км, что составляет $25 \%$ от протяженности проводов этих линий в Украине. В связи с этим спрос на контактные провода довольно значителен и определяется необходимостью замены большого количества контактных сетей вследствие накопившегося за последний период износа подвески, прокладки новых магистралей, а также перевода железнодорожного состава на повышенные скорости движения.

Последний фактор предполагает использование более прочных марок проводных материалов ( по сравнению с медью) или новых, более прочных конструкций проводов. Это связано с усилением колебательных волновых процессов, происходящих в контактной подвеске, необходимостью увеличения теплостойкости проводных систем, в том числе и путем повышения температуры рекристаллизации используемых материалов в условиях эксплуатации [2-5]. Важной задачей является также повышение производительности процессов изготовления проводов.

Целью работы является анализ наиболее современных технологий и проектов, воплощенных в производство, и выдвижение новых технологических решений, связанных с изготовлением контактного провода.

Способы изготовления контактного провода в значительной мере зависят от его конструкции. Можно выделить три основных типа контактных проводов. К их числу относятся: провод, выполненный из однородного металла или сплава на его основе; провод, выполненный из металла, который имеет переменный химический состав, изменяющийся, например, от химического состава меди до химического состава сплава на ее основе или переменную структуру; провод армированный, заведомо неоднородный по своему поперечному сечению, состоящий из стальной сердцевины и медной (иногда алюминиевой) оболочки.

Для получения провода, выполненного из однородного металла или сплава на его основе используют традиционно процессы обработки давлением, способные обеспечить редуцирование, полученной полунепрерывным способом литья, заготовки диаметром 100 мм и более с коэффициентом вытяжки 100 и более. Сегодня эта задача часть решается путем применения процессов горячей сортовой прокатки или прессования, которые способны обеспечить такую деформацию при многопроходной прокатке, либо за один проход пресса. 
Однако длина слитка в последнем случае ограничена и его масса редко превышает 100 кг, а число стыков, выполненных пайкой или сваркой на одну тонну провода по условиям стандарта [1] должно быть не более четырех.

Преимущественно при получении провода процессы прессования и горячей прокатки сочетают с процессом холодной прокатки и (или) волочения в монолитных и роликовых волоках, который используют как основной в формировании профиля провода из круглой катаной или прессованной заготовки, а также в роли финишной операции для получения более высоких показателей точности размеров и формы провода $[6,7]$. Однако, следует иметь в виду, что процесс волочения, особенно при использовании монолитных волок, имеет неблагоприятную схему напряженного состояния металла с преобладанием растягивающих напряжений. Это усугубляется также значительной неравномерностью деформации при волочении фасонных профилей из заготовки круглого сечения, что порождает высокий уровень остаточных напряжений в изделии, которые существенно снижают предел прочности провода на растяжение.

Для производства заготовок контактного провода из легированных сплавов применяют методы введения лигатуры непосредственно в кристаллизатор машины непрерывного литья [8-11].

Новые технологические возможности появились с реализацией процесса непрерывной прокатки, совмещенной с непрерывным литьем. Эти процессы в последнее время получили широкое распространение, особенно на зарубежных предприятиях, и позволяют изготавливать провод необходимой строительной длины без стыков в бухтах с большой массой [12-14].

К их числу можно отнести совмещенные процессы литья относительно крупной заго-

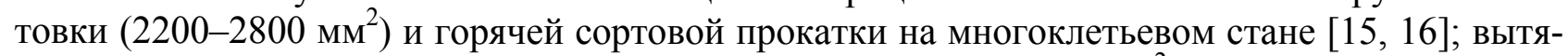
гивание из расплава тонкомерных заготовок сечением около $50 \mathrm{~mm}^{2}$ с последующей холодной деформацией, что обеспечивает возможность, отказавшись от операции горячей сортовой прокатки, сразу перейти к волочению; процессы литья заготовок среднего сечения (око-

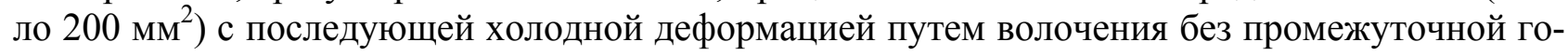
рячей деформации.

Стремление повысить прочностные характеристики провода и его износостойкость привели к разработке технологий, обеспечивающих получение провода с переменным химическим составом металла, из которого он выполнен [17-19], или переменной структурой $[20,21]$. Номенклатура сплавов включает деление на медь, бронзы и легированные сплавы меди. В качестве легирующих элементов используют кадмий, магний, марганец, хром, цирконий, кадмий и др. Так, например, контактный провод [17] состоит из сердечника, выполненного из медного сплава и оболочки, выполненной из меди, в котором переходная зона между оболочкой и сердечником имеет химический состав, плавно изменяющийся от химического состава меди до химического состава сплава, при этом в качестве медного сплава применена магниевая, или кадмиевая, или магниево-циркониевая, или циркониевая бронза; или магниевая, или циркониевая, или оловянная низколегированная медь, а такая конфигурация контактного провода достигается путем получения расплава меди в индукционной печи с последующей ее полунепрерывной разливкой с подачей в кристаллизатор легирующего элемента (например, кадмия) в виде проволоки, которая расплавляется в расплаве основного металла - меди и диффундирует в него с образованием сплава.

Однако, указанные [17-21] и другие технологии этого направления, несмотря на возможность достижения достаточно высоких служебных характеристик провода, достаточно сложны.

Приемлемым вариантом изготовления провода, особенно для железных дорог, является вариант получения армированного (биметаллического) провода, внутри которого имеется сердечник из прочного материала, например, стали, предназначенной для восприятия напряжений от тяжести провода, налипшего снега или наледи, а также ветровых нагрузок. При этом снаружи провод выполнен из материала с высокой электропроводностью. 
Большое количество технологий производства такого типа провода разработано и продолжает разрабатываться в мире $[20,22,23]$ хотя есть проблемы в переработке изношенных проводов. Например, контактный сталеалюминиевый провод [22] получают путем наложения на сердечник на алюминиевом прессе кольцевого слоя выпрессованного алюминия с помощью технологического инструмента в виде матрицы и дорна с последующими охлаждением и намоткой на барабан. Способ [23] армирования подвесного контактного провода заключается в укладке армирующей проволоки в выдавленную в заготовке вдоль ее продольной оси канавку, которую затем закрывают, сдвигая ее стенки путем холодного деформирования, после чего стенки канавки сваривают. Возможно также получение биметаллического контактного провода [20] путем подачи одновременно с расплавом в пространство между желобом вращающегося кристаллизатора и бесконечной лентой предварительно изогнутого по радиусу металлического прутка со скоростью, равной скорости непрерывного литья, с последующими после кристаллизации расплава прокаткой и калибровкой волочением полученной фасонной заготовки. Описанные и другие способы получения армированного провода характеризуются технологической сложностью и низкой производительностью.

Следует обратить внимание на то, что в последнее время активно развивается и используется технология Conform [24], позволяющая формировать конечный профиль длинномерных изделий с высоким качеством поверхности. Технология Conform, на наш взгляд, открывает широкие возможности и в изготовлении проводов специального назначения [25, 26], в том числе и армированных композитных проводов электротехнического назначения [27-29].

Далее приведем некоторые новые решения в использовании Conform-процесса для изготовления армированного электроконтактного провода, в том числе и с композитным токопроводящим слоем.

Известен способ [28] изготовления провода круглого сечения на основе Conformпроцесса путем экструдирования меди или медного сплава вокруг стальной проволоки с последующей горячей прокаткой, при этом, сначала медный материал подают в зазор между вращающимся ротором с кольцевой проточкой и башмаком, который охватывает часть этого ротора, в результате чего под действием фрикционных сил на поверхностях проточки ротора и башмака медный материал разогреваясь, поступает в экструдийный контейнер с фильерой, в который после предварительного индукционного нагрева также подают и стальную проволоку для покрытия медным материалом, причем после того как это пластическое покрытие медным материалом окончательно сформируется с помощью фильеры вокруг стальной проволоки, его дополнительно подвергают горячей прокатке в валках при температуре $400{ }^{\circ} \mathrm{C}$ и более с обжатием от 10 до $40 \%$.

Известен также способ [29] изготовления троллейного провода на основе Conformпроцесса, который заключается в конформном кольцевом покрытии стальной проволоки термостойким медным сплавом с последующим приданием периферийному слою покрытия необходимого профиля поперечного сечения путем прокатки в калиброванных валках или волочения через фильеру.

С учетом недостатков описанных выше способов, предложен новый способ [30] изготовления армированного подвесного контактного (троллейного) провода на основе Conformпроцесса, который заключается в конформном покрытии предварительно подогретой стальной проволоки медью или медным сплавом любого состава путем непрерывного прессования (экструзии) медного материала в экструдийном контейнере с фильерой с использованием башмака и калиброванного вращающегося ротора, в котором стальную проволоку в количестве одной или двух разнесенных жил одинакового или разного диаметра предварительно подвергают деформации в двух последовательно установленных волоках с обжатием от 1 до $2 \%$ в каждой, а затем с помощью направляющих ниппелей подают в рабочую полость экструдийного контейнера, заполняемую пластичным медным материалом, при этом пластичное медное покрытие проволоки и окончательные форма и размеры, соответствующие заданным форме и размерам готового армированного подвесного контактного (троллейного) провода, формируются с помощью фильеры, закрепленной на выходе из составного 
экструдийного контейнера с поперечным разъемом по рабочей полости, часть которой занимает вставка в виде цилиндра, одно из оснований которого выполнено наклонным, кроме того, в изолированную полость, предусмотренную на входе в первую волоку для предварительной деформации жил стальной проволоки, подают поверхностно-активную водновоздушную смесь, например, поливинил-ацетатного клея, а в герметичную полость, выполненную между первой и второй волоками для предварительной деформации стальной проволоки, вводят медный или медно-графитный порошок преимущественно под давлением.

Схема агрегата для изготовления армированного электроконтактного провода приведена на рис. 1.

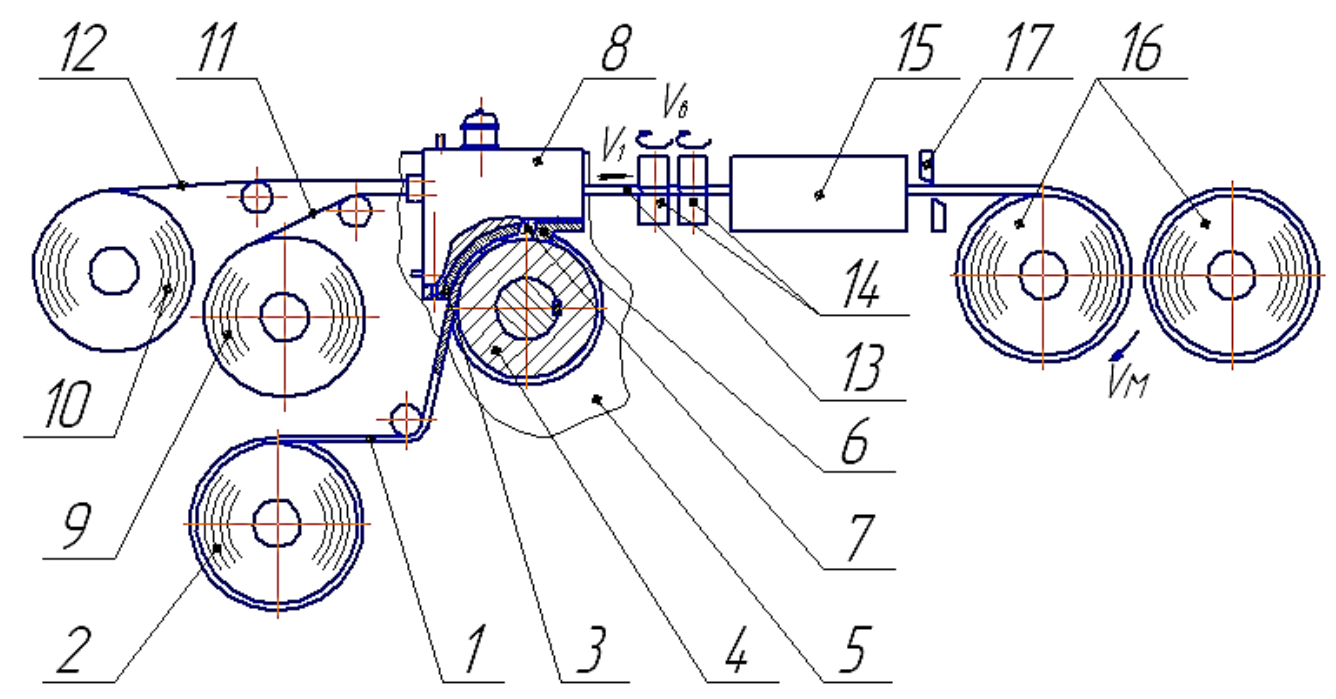

Рис. 1. Схема агрегата для изготовления армированного подвесного контактного (троллейного) провода

Заготовку 1 (см. рис. 1) из медного материала с разматывателя 2 подают в зазор между башмаком 3 и калиброванным вращающимся ротором 4, размещенными в станине 5. Заготовка 1 под действием сил трения втягивается в указанный зазор, разогреваясь и становясь весьма пластичной. Достигнув упора 6 образовавшийся пластичный медный материал 7, поступает в волочильно-экструдийний блок 8 (рис. 2), который также установлен в станине 5 . Одновременно с этим в волочильно-экструдийний блок 8 с разматывателей 9 и 10 подают одну или две жилы стальной проволоки 11 и 12 одинакового или различного диаметра, которые подвергают конформному покрытию пластичным медным материалом 7 с образованием готового армированного подвесного контактного (троллейного) провода 13, извлекаемого из волочильно-экструдийного блока 8 с помощью тянущих валков 14. После охлаждения в камере 15 готовый провод 13 сматывают в бунт на одной из моталок 16, работающих поочередно. Для разделения провода 13 после того, как сформирован бунт необходимой массы, служат ножницы 17.

Перед пуском агрегата для изготовления армированного провода, предварительно заостренные на заправочную длину концы жил стальной проволоки 11,12 с помощью проводки 18 пропускают свободно через рабочие каналы первой 19 и второй 20 волок и ориентируют с помощью ниппелей 21 в проеме рабочего канала фильеры 22, закрепленной на выходе из составного экструдийного контейнера 23, часть рабочей полости 24 которого занимает вставка 25 , изготовленная в виде цилиндра, одно из оснований которого выполнено наклонным. Заостренные концы жил стальной проволоки 11, 12 крепят в цанговом зажиме, связанным с одним из концов заправочного троса (не показаны), второй конец которого фиксируют на барабане одной из моталок 16. 

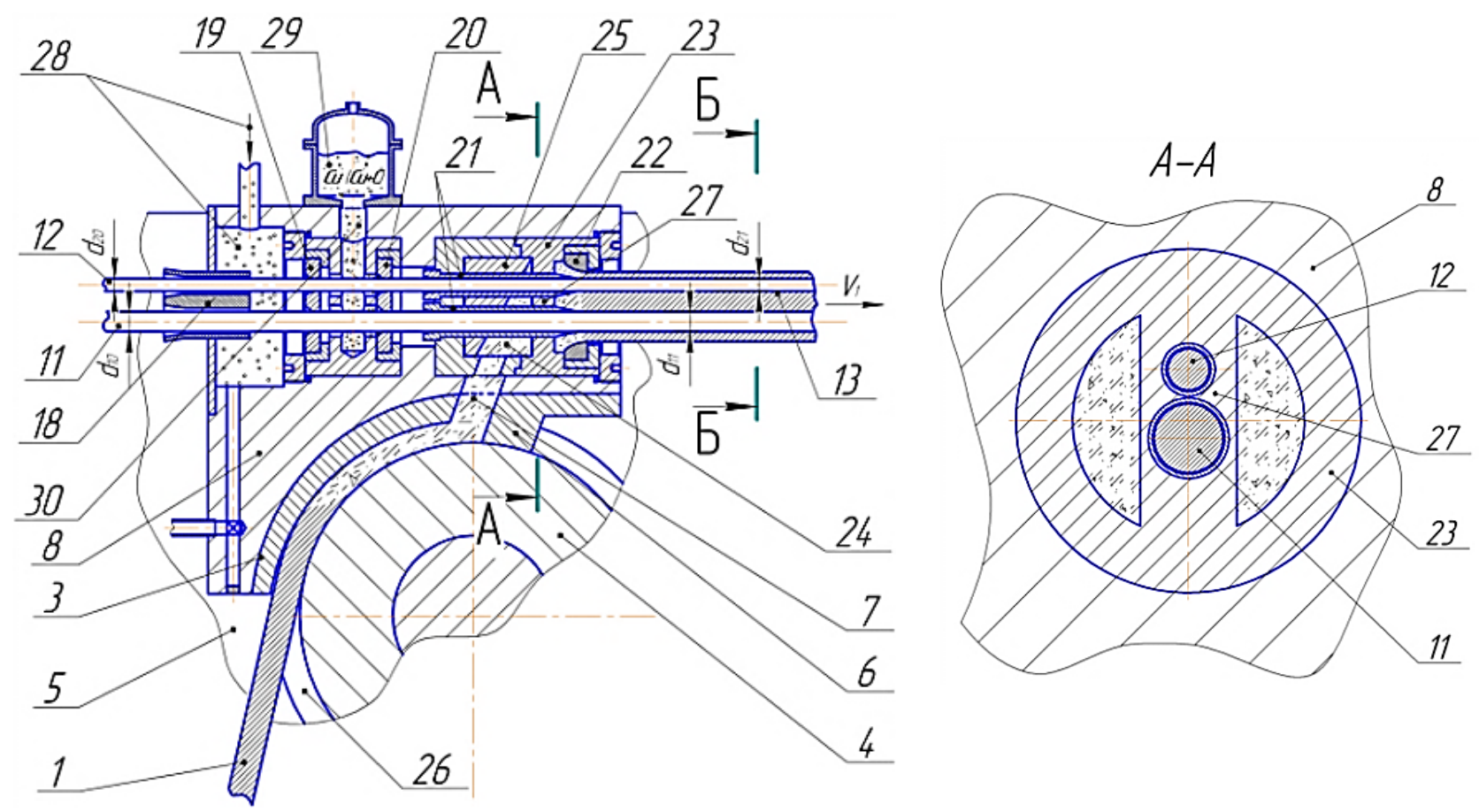

Рис. 2. Схема волочильно-экструдийного блока

Поворотом барабана моталки 16 жилы стальной проволоки 11, 12 с помощью цангового зажима и заправочного троса перемещают к входу в волоку 19 незаостренных участков жил стальной проволоки 11,12 с исходными диаметрами $\mathrm{d}_{1 \mathrm{o}}$ и $\mathrm{d}$ 20. Моталкой 16 создают натяжение жил стальной проволоки 11, 12 и одновременно включают привод калиброванного ротора 4, предварительно заправив заготовку 1 из медного материала в зазор, образованный башмаком 3 и ручьем 26 калиброванного ротора 4. Таким образом, начинают процесс образования пластичного медного материала 7, который под действием сил трения, возникающих на рабочей поверхности ручья 26 калиброванного ротора 4, направляемый наклонной поверхностью основания вставки 25, заполняет свободную часть рабочей полости 24 экструдийного контейнера 23 и, обтекая его перемычку 27, поступает в фильеру 22 с ориентированными в проеме ее рабочего канала с помощью ниппелей 21 жилами стальной проволоки 11, 12. В фильере 22 собственно и осуществляется пластическое медное покрытие жил стальной проволоки 11, 12 и формирование поперечного профиля армированного провода 13 в соответствии с его заданными размерами и формой (рис. 3).

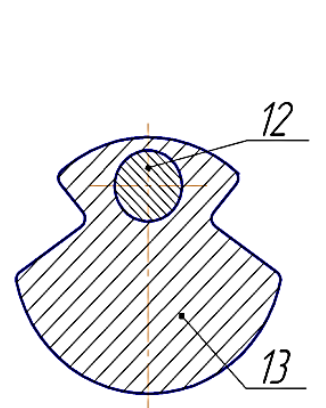

a

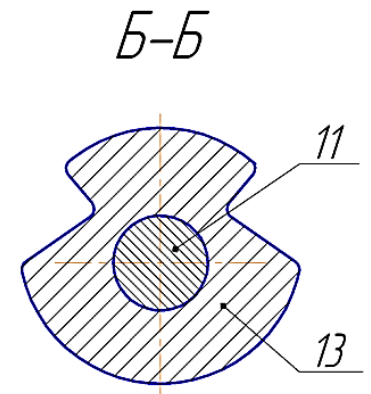

6

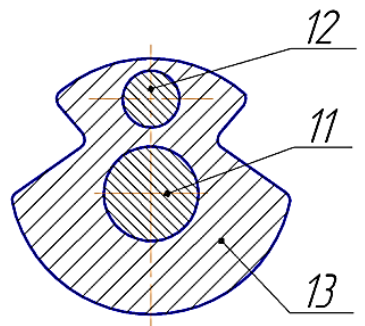

B

Рис. 3. Поперечный разрез готового армированного подвесного контактного (троллейного) провода

a-co стальной проволокой в захватной головке; б-со стальной проволокой в основании (б); в - с жилами стальной проволоки в захватной головке и основании 
При входе полного профиля провода 13 в тянущие валки 14, включают их привод и убирают заправочный трос с цанговым зажимом, а после того как передний конец готового провода 13 достигнет барабана первой по ходу моталки 16 его крепят на барабане этой моталки и включают ее привод. Таким образом, за счет работы тянущих валков 14 моталки 16 и осевых сил, возникающих при выдавливании пластичного медного материала 7 из рабочей полости 24 экструдийного контейнера 23 создают суммарную осевую силу, которая обеспечивает перемещение готового провода 13 и предварительную деформацию жил стальной проволоки 11,12 в последовательно установленных волоках 19, 20. При этом скорость перемещения провода 13 $\left(\mathrm{V}_{1}\right)$, окружные скорости тянущих валков $14\left(\mathrm{~V}_{\text {в }}\right)$ и барабана моталки $16\left(\mathrm{~V}_{\mathrm{M}}\right)$ синхронизированы.

Обжатие жил стальной проволоки 11, 12 в волоках 19, 20 в пределах $1 . . .2 \%$ в каждой из них обеспечивает предварительный разогрев стальной проволоки за счет работы сил трения на рабочих контактных поверхностях волок 19, 20 и удаление окисной пленки с поверхностей жил стальной проволоки 11, 12. Это способствует лучшему их сцеплению с пластичным медным материалом 7 в рабочей зоне фильеры 22. Наряду с этим, поверхности жил стальной проволоки 11, 12 подвергаются наклепу, а их сердцевина остается недеформированной (мягкой), что обеспечивает, с одной стороны, более высокую прочность провода 13 в целом, а с другой стороны достаточно высокую степень его податливости (пониженную жесткость).

Перед обжатием жил стальной проволоки 11, 12 в волоках 19, 20 в изолированную полость 28 подают поверхностно-активную водно-воздушную смесь, например, поливинилацетатного клея, которая служит в качестве смазки при деформации жил стальной проволоки 11, 12 в первой волоке 19. Тончайшая пленка смазки, которая остается на поверхностях жил проволоки на выходе из волоки 19 способствует более эффективному втягиванию медного или медно-графитового порошка в очаг деформации второй волоки 20 , который с помощью аккумулятора 29 подают преимущественно под давлением в герметичную полость 30, образованную между первой 19 и второй 20 волоками. Названный порошок выполняет роль смазки при деформации жил стальной проволоки 11, 12 во второй волоке 20 и сцепляясь с поверхностями этих жил, наряду с другими указанными выше приемами, способствует более прочному соединению жил стальной проволоки 11, 12 с пластичным медным материалом 7 в рабочей зоне фильеры 22.

Следует отметить, что в случае изготовления армированного электроконтактного про-

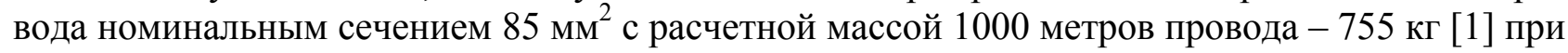
использовании для армирования провода двух жил 11, 12 проволоки из малоуглеродистой стали с исходными диаметрами $\mathrm{d}_{10}=4,0$ мм и $\mathrm{d}_{20}=2,5$ мм с относительными обжатиями $\varepsilon=2 \%$ в каждой из волок 19, 20 экономия меди за счет ее замещения жилами стальной проволоки из расчета на 1000 метров готового армированного электроконтактного провода указанного сечения, составит 143,3 кг, а масса провода, ввиду меньшего значения плотности стали, уменьшится на 16,4 кг.

Если задача обеспечения более высоких прочностных характеристик провода не стоит, снижение его массы и уменьшение расхода дорогостоящей меди можно обеспечить, используя в качестве материала жил 11, 12 алюминий или сплавы на его основе.

Новые возможности в изготовлении композитного провода электротехнического назначения открывает способ ${ }^{1}$, который основан на технологических приемах способа [30], описанного выше, и предполагает, что при изготовлении провода, используемая в качестве арматуры (или для замещения некоторого объема меди), металлическая проволока после волочения подвергается многократному пластическому покрытию в любом сочетании цветными металлами или сплавами на их основе в последовательно расположенных экструдийных контейнерах с фильерами, в которых формируются промежуточные слои покрытия и окончательный с заданными размерами профиль провода.

Способ осуществляют на агрегате, схема которого представлена на рис. 4.

\footnotetext{
${ }^{1}$ Положительное решение о выдаче патента: Спосіб виготовлення композитного дроту електротехнічного призначення / В. А. Федорінов, О. В. Барабаш, М. В. Федоринорв та ін. - № U201903441 ; заявл. 05.04.2019
} 


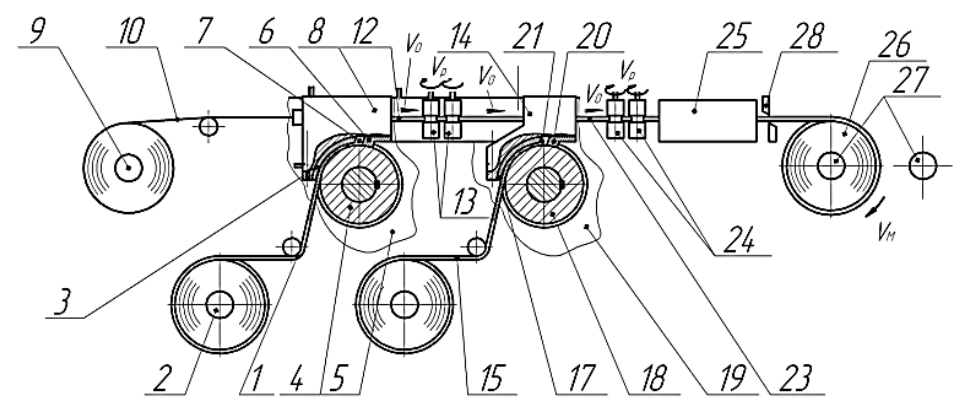

Рис. 4. Схема агрегата для изготовления композитного провода

Заготовку 1 (см. рис. 4) из цветного металла или сплава любого состава с разматывателя 2 подают в зазор между башмаком 3 и калиброванным вращающимся ротором 4, которые размещены в станине 5. Достигнув упора 6, образовавшийся пластичный материал 7 поступает в волочильно-экструдийный блок 8 (рис. 5). Одновременно с этим в волочильноэкструдийный блок 8 с разматывателя 9 подают металлическую проволоку 10 из стали или цветного металла, или сплава, которую подвергают конформному покрытию пластичным материалом 7, образуя первый слой покрытия 11 площадью $\mathrm{F}_{1}$ и промежуточный профиль 12 площадью $\mathrm{F}_{\text {п1 }}$ композитного провода, который вытягивают из волочильно-экструдийного блока 8 с помощью приводных профилированных тянущих роликов 13 и направляют в экструдийный блок 14. Одновременно с этим заготовку 15 из другого цветного металла или сплава любого состава с разматывателя 16 подают в зазор между башмаком 17 и калиброванным вращающимся ротором 18, которые размещены в станине 19. Достигнув упора 20 , образовавшийся другой пластичный материал 21 поступает в экструдийный блок 14. Таким образом, ранее образованный промежуточный профиль 12 подвергают конформному покрытию другим пластичным материалом 21, нанося второй слой покрытия 22 площадью $\mathrm{F}_{2}$ (в рассматриваемом случае наружный слой) и получают в итоге готовый композитный провод 23 электротехнического назначения (с двухслойным покрытием) площадью $\mathrm{F}_{\text {п2}}$, который вытягивают из экструдийного блока 14 с помощью приводных профилированных тянущих роликов 24 и направляют в охладитель 25. После охлаждения готовый провод 23 подвергают смотке в бунт 26 на одной из моталок 27, работающих поочередно. Для разделения провода 23 после того, как сформирован бунт необходимой массы, служат ножницы 28.

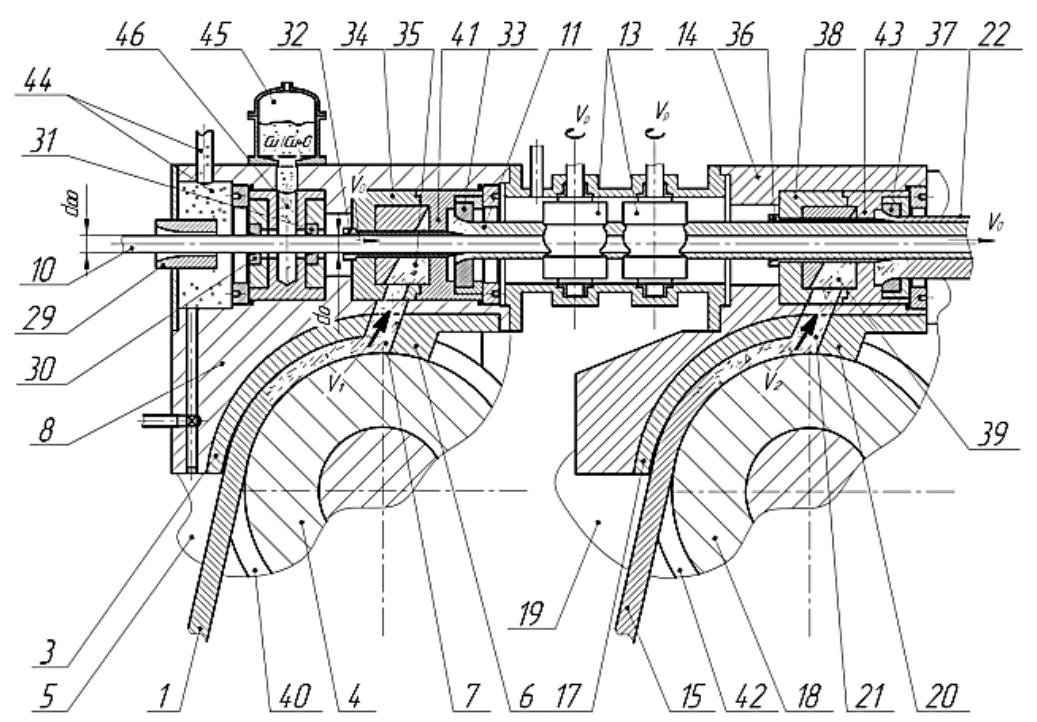

Рис. 5. Схема взаимодействия экструдийных блоков

При необходимости нанесения большего числа слоев покрытия увеличивают количество экструдийных блоков. 
Перед пуском агрегата предварительно заостренный на заправочную длину конец металлической проволоки 10 с помощью проводки 29 (см. рис. 5) пропускают свободно через рабочие каналы первой 30 и второй 31 волок и ориентируют с помощью ниппеля 32 в проеме рабочего канала фильеры 33, закрепленной на выходе из экструдийного контейнера 34 с рабочей полостью 35 волочильно-экструдийного блока 8. Далее упомянутый передний конец проволоки 10 пропускают между тянущими роликами 13, вводят в ниппель 36 и проем рабочего канала фильеры 37 , закрепленной на выходе из экструдийного контейнера 38 с рабочей полостью 39 экструдийного блока 14, пропускают между тянущими роликами 24 и крепят в цанговом зажиме заправочного троса, свободный конец которого фиксируют на барабане первой по ходу моталки 27. Поворотом барабана моталки 27 металлическую проволоку 10 с помощью заправочного троса с цанговым зажимом перемещают до входа в волоку 30 незаостренной части проволоки 10 с исходным диаметром $\mathrm{d}_{00}$. Моталкой 27 создают натяжение проволоки 10 и одновременно включают привод калиброванного вращающегося ротора 4 с подачей заготовки 1 в зазор, образованный башмаком 3 и ручьем 40 этого ротора. Так начинают процесс образования пластичного материала 7 для нанесения первого слоя покрытия 11 площадью $\mathrm{F}_{1}$ и образования промежуточного профиля 12 площадью $\mathrm{F}_{\text {п1 }}$ изготавливаемого композитного провода. Пластичный материал 7, обтекая перемычку 41 экструдийного контейнера 34, поступает в фильеру 33 с ориентированной в проеме ее рабочего канала с помощью ниппеля 32 проволокой 10 диаметром $\mathrm{d}_{0}$ после деформации в волоках 30 и 31. В фильере 33 формируют первый слой покрытия 11 металлической проволоки 10 с получением промежуточного профиля 12. При его входе в тянущие ролики 13 с калиброванными бочками, включают привод роликов и с помощью ниппеля 36 ориентируют профиль 12 в проеме рабочего канала фильеры 37. Включают привод калиброванного вращающегося ротора 18 экструдийного блока 14, предварительно заправив заготовку 15 в зазор, образованный башмаком 17 и ручьем 42 калиброванного ротора 18. Этим действием начинают процесс образования пластичного материала 21 из другого цветного металла или сплава любого состава для нанесения второго слоя покрытия 22 площадью $\mathrm{F}_{2}$ с образованием готового композитного провода 23 площадью $\mathrm{F}_{\text {п2 }}$. Пластичный материал 21, обтекая перемычку 43 экструдийного контейнера 38 , поступает в фильеру 37 с ориентированным с помощью ниппеля 36 в проеме ее рабочего канала промежуточным профилем 12. В фильере 37 формируют второе пластичное покрытие и завершают получение готового композитного провода 23 с заданными размерами и формой. Схема формирования двух слоев покрытия при изготовлении композитного электроконтактного провода приведена на рис. 6.

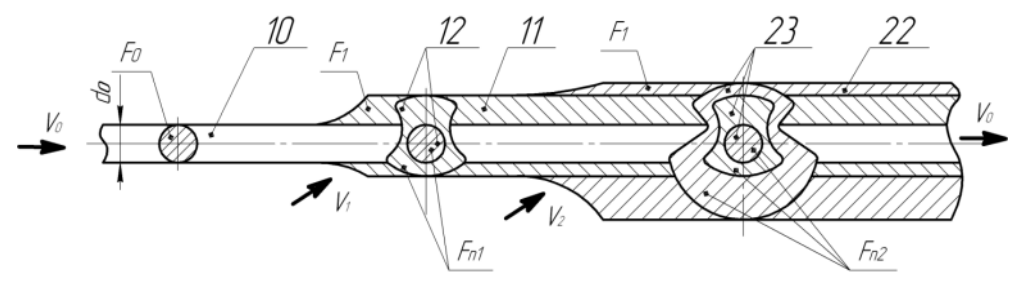

Рис. 6. Схема формирования слоев покрытия при изготовлении композитного электроконтактного провода

При входе готового провода 23 в тянущие ролики 24 с соответствующей профилю провода калибровкой их бочек, включают привод роликов и убирают заправочный трос с цанговым зажимом, а после того как передний конец готового композитного провода 23 достигнет барабана первой по ходу моталки 27, его крепят на барабане этой моталки и включают привод последней. Таким образом, за счет работы тянущих роликов 13 и 24, моталки 27 и осевых сил, возникающих при выдавливании пластичных материалов 7 и 21 из рабочих полостей 35 и 39 экструдийных контейнеров 34 и 38 создают суммарную осевую силу, обеспечивающую перемещение готового композитного провода 23 и предварительную деформацию 
металлической проволоки 10 с диаметра $\mathrm{d}_{00}$ до диаметра $\mathrm{d}_{0}$ в последовательно размещенных волоках 30 и 31. При этом скорость перемещения провода с промежуточным профилем 12 и в готовом состоянии 23, а также окружные скорости вращения $\mathrm{V}_{\mathrm{p}}$ тянущих роликов 13 и 24 и барабана моталки $27\left(\mathrm{~V}_{\mathrm{m}}\right)$ синхронизированы и равны скорости $\mathrm{V}_{0}$ выхода металлической проволоки 10 из второй волоки 31.

При настройке агрегата для изготовления композитного провода назначают частоту вращения калиброванных роторов 4 и 18 таким образом, чтобы скорости подачи пластического покрытия - пластичных материалов 7 и 21, формирующих каждый из слоев (11 и 22), удовлетворяла выполнению условия постоянства секундных объемов образующегося покрытия с учетом площади поперечного сечения $\mathrm{F}_{0}$ и скорости $\mathrm{V}_{0}$ движения металлической проволоки 10 после ее пластической деформации волочением.

Это условие для рассматриваемого случая имеет вид:

$$
\mathrm{V}_{1} \mathrm{~F}_{1}=\mathrm{V}_{2} \mathrm{~F}_{2}=\mathrm{V}_{0} \mathrm{~F}_{0}
$$

где $\mathrm{V}_{1}, \mathrm{~V}_{2}$ - скорости подачи пластичных материалов в рабочие полости экструдийных контейнеров;

$\mathrm{F}_{1}, \mathrm{~F}_{2}$ - площади поперечных сечений покрытий пластичными материалами;

$\mathrm{V}_{0} \mathrm{~F}_{0}$ - постоянная величина скоростной настройки для конкретного профиля композитного провода.

В общем случае, при нанесении большого числа слоев покрытия, выражение (1) можно записать в виде:

$$
\mathrm{V}_{1} \mathrm{~F}_{1}=\mathrm{V}_{2} \mathrm{~F}_{2}=\ldots=\mathrm{V}_{\mathrm{n}} \mathrm{F}_{\mathrm{n}}=\mathrm{V}_{0} \mathrm{~F}_{0},
$$

где $\mathrm{V}_{\mathrm{n}}$ - скорость подачи пластичного материала в рабочую полость последнего (n) экструдийного контейнера;

$\mathrm{F}_{\mathrm{n}}$ - площадь поперечного сечения последнего (n) слоя покрытия пластичным материалом.

Обозначив площади поперечного сечения промежуточных профилей провода как $\mathrm{F}_{\text {п1}}$; $\mathrm{F}_{\Pi 2} \ldots \mathrm{F}_{\Pi_{\mathrm{n}-1}}$, а готового профиля провода - через $\mathrm{F}_{\Pi_{\mathrm{n}}}$, имеем:

$$
\begin{aligned}
& F_{1}=F_{\Pi 1}-F_{0} ; F_{2}=F_{\Pi 2}-F_{\Pi 1}=F_{\Pi 2}-\left(F_{0}+F_{1}\right) ; \ldots \\
& \ldots ; F_{n}=F_{\Pi_{n}}-F_{\Pi_{n-1}}=F_{\Pi_{\Pi}}-\left(F_{0}+F_{1}+F_{2}+\ldots+F_{n-1}\right) .
\end{aligned}
$$

Тогда условие (2) приобретает вид:

$$
\mathrm{V}_{1}\left(\mathrm{~F}_{\Pi 1}-\mathrm{F}_{0}\right)=\mathrm{V}_{2}\left[\mathrm{~F}_{\Pi 2}-\left(\mathrm{F}_{0}+\mathrm{F}_{1}\right)\right]=\ldots=\mathrm{V}_{\mathrm{n}}\left[\mathrm{F}_{\Pi_{\mathrm{n}}}-\left(\mathrm{F}_{0}+\mathrm{F}_{1}+\mathrm{F}_{2}+\ldots+\mathrm{F}_{\mathrm{n}-1}\right)\right]=\mathrm{V}_{0} \mathrm{~F}_{0} .
$$

Из выражения (3) находят скорости подачи пластичных материалов в рабочие полости экструдийных контейнеров, обеспечивающие выполнение условия постоянства секундных объемов и, как следствие, сплошность слоев образующегося покрытия:

$$
\mathrm{V}_{1}=\frac{\mathrm{V}_{0} \mathrm{~F}_{0}}{\mathrm{~F}_{\mathrm{\Pi} 1}-\mathrm{F}_{0}} ; \mathrm{V}_{2}=\frac{\mathrm{V}_{0} \mathrm{~F}_{0}}{\mathrm{~F}_{\mathrm{n} 2}-\left(\mathrm{F}_{0}+\mathrm{F}_{1}\right)}=\ldots=\mathrm{V}_{\mathrm{n}}=\frac{\mathrm{V}_{0} \mathrm{~F}_{0}}{\mathrm{~F}_{\mathrm{\Pi}_{\mathrm{n}}}-\left(\mathrm{F}_{0}+\mathrm{F}_{1}+\mathrm{F}_{2}+\ldots+\mathrm{F}_{\mathrm{n}-1}\right)}
$$

$\mathrm{C}$ целью повышения производительности агрегата, предназначенного для получения композитного контактного провода исходная длина стальной проволоки 10 на разматывателе 9 должна быть больше и, по крайней мере, превышать требуемую строительную длину готового композитного провода 23 в $3 . .5$ раз. Здесь следует отметить, что уровень производительности процесса возрастет в большей степени, если в головной части агрегата для изготовления композитного провода реализовать известные подходы, обеспечивающие 
«бесконечный» процесс, в числе которых в первую очередь следует предусмотреть стыковку задних концов металлической проволоки 10 и заготовок 1 и 15 в расходуемых бунтах с передними концами проволоки и заготовок в сменных (новых) бунтах.

Использование предложенных способов (см. рис. 1 и рис. 4) для изготовления армированного и композитного электроконтактного провода позволяет расширить его сортамент, повысить производительность и выход годной продукции, улучшить качество провода, снизить капитальные и текущие затраты, связанные с изготовлением провода.

\section{ВЫВОДЫ}

Проведенный анализ позволяет сделать следующие выводы:

1. Способы изготовления электроконтактного провода в значительной мере определяются одним из его типов, к числу которых относят: провод, выполненный из однородного металла или сплава на его основе; провод, выполненный из металла (или сплава), который имеет переменный химический состав; провод армированный.

2. Успехи, достигнутые в мировой практике производства электроконтактного провода из меди и ее сплавов, связанные с увеличением строительной длины провода, повышением производительности процессов его изготовления, улучшением потребительских свойств готовых изделий, достигнуты за счет применения непрерывных способов получения и обработки заготовок, в том числе и с заданными видами структуры и изменяющегося по сечению провода химического состава.

3. В мире разработано и продолжает разрабатываться большое количество технологий производства армированного (биметаллического) провода, внутри которого имеется сердечник из прочного материала, несмотря на определенные трудности в переработке изношенных проводов.

4. Широкие возможности в изготовлении электроконтактного провода, в том числе и армированного, предоставляет технология Conform. На основе этой технологии предложены новые способы изготовления электроконтактного армированного и композитного провода.

\section{СПИСОК ИСПОЛЬЗОВАННОЙ ЛИТЕРАТУРЫ}

1. ГОСТ 2584-86. Провода контактные из меди и ее сплавов. М. : Издательство стандартов, 1986. 12 с.

2. Gershman I. S., Mirchos N. V. Requirements to contact wires for high-speed railway transport. Вестник научно-исследовательского института железнодорожного транспорта. 2011. 3. С. 13.

3. Мочинага И. Тенденции в развитии тягового электроснабжения. Железные дороги мира. 2002. 6. С. 20.

4. Боков Н. Ф. [и др.]. Организация выпуска в ОАО «Каменск-Уральский завод по обработке цветных металлов» нестандартных профилей из электротехнической меди. Производство проката. 2010. 8. С. 29.

5. Берент В. Я. Совершенствование проводов контактной сети. Вестник научно-исследовательского института железнодорожного транспорта. 2012. 3. С. 40-45.

6. Моргунов В. В., Якубович Е. А. Производство контактного провода на основе комплекснолегированной меди. Современные материаль, техника и технологии. 2016. 3(4).

7. Славин В. С., Норец А. И. Способ волочения провода контактного: пат. 2492010 Российская Федерация: МПК В21С 1/00. Заявл. 20.03.2012; опубл. 10.09.2013.

8. Логинов Ю. Н., Мысик Р. К. Полунепрерывное и непрерывное литье меди и ее сплавов при производстве контактного провода. Литейщик России. 2005. № 1. С. 34.

9. Поручиков Ю. П., Мысик Р. К., Логинов Ю. Н. и др. Способ обработки металла легирующим компонентом при непрерывном литье заготовок: пат. 1194894 СССР. Опубл. 30.11.1985.

10. Гершман И. С., Гершман Е. И. Способ изготовления электроконтактного провода и электроконтактный провод: пат. 2540944 Российская Федерация: МПК В60М 1/13, В21В 1/46, Н01В 1/02. Заявл. 26.09.2013; опубл. 10.02.2015, Бюл. № 4.

11. Берент В. Я. Способ изготовления контактных проводов: пат. 2236918 Российская Федерация: МПК В21В 1/46. Заявл. 17.01.2002; опубл. 27.09.2004. 2013. $336 \mathrm{c}$.

12. Райков Ю. Н. Экономика предприятий обработки цветных металлов. М. : Интерметинжиниринг,

13. Сидельников С. Б. Классификация и области применения совмещенных и комбинированных процессов обработки цветных металлов и сплавов. Известия вузов. Цветная металлургия. 2005. № 3. С. 45. 
14. Чеботарев В. А., Самсонов А. А. Литейно-прокатные агрегаты для производства катанки, листов и лент из цветных металлов. Тяжелое машиностроение. 2007. № 5. С. 20.

15. Логинов Ю. Н., Зуев А. Ю., Инатович Ю. В. Анализ сортовой прокатки кислородосодержащей меди с учетом немонотонности характеристик упрочнения. Цветные металльл. 2012. № 7. С. 77.

16. Логинов Ю. Н., Зуев А. Ю. Формоизменение и сопротивление деформации анизотропной непрерывно-литой меди. Заготовительные производства в машиностроении. 2011. № 1. С. 32.

17. Мысик Р. К., Логинов Ю. Н., Скрыльников А. И. Контактный провод: пат. 2261185 Российская Федерация: МПК В60М 1/13. Заявл. 01.10.2003; опубл. 27.09.2005, Бюл. № 27.

18. Goto M., Kawakita S., Mae Y. and other. Method for producing wire for electric railways: patent US № 5391243. Publ. 21.02.1995.

19. Nagasawa H., Aoki S., Kawakita S. Production of copper alloy trolley wire and hanging stringing: patent JP № 6154838. Publ. 03.06.1994.

20. Алехин В. Л., Антропов В. Н., Буше Н. А. и др. Способ изготовления контактного провода: пат. 1101323 СССР: МПК В22D 11/06. Заявл. 10.01.1983; опубл. 07.07.1984, Бюл. № 25.

21. Берент В. Я. Способ получения контактных проводов из сплавов на основе меди: пат. 2162764 Российская Федерация. Опубл. 10.02.2001.

22. Самойленко А. К., Мочилин Г. Л., Руденко В. М. и др. Способ изготовления контактного сталеалюминиевого провода: пат. 2351485 Российская Федерация: МПК В60М 1/13. Заявл. 30.10.2006; опубл. 10.04.2009.

23. Андреев А. В. Способ армирования подвесногоконтактного провода: пат. 2195730 Российская Федерация: МПК Н01В 13/22, В60М 1/13. Заявл. 23.06.2000; опубл. 27.12.2002. 29.02.1872.

24. Греен Дерек. Экструзия: пат. СА59792А Канада: МПК В21С 23/00. Заявл. 12.03.1971; опубл

25. Ohata Yosuke. Copper coated steel stock, copper coated steel bar for grounding electrode, and manufacturing method therefor: пат. JP2002254108 Японія: МПК В21С 23/14, В21C 23/21, В21C 37/00, Н02G 13/00. Заявл. 28.02.2001; опубл. 10.09.2002.

26. Федорінов В. А., Грибков Е. П., Федоринов М. В. Спосіб виробництва композиційного дроту: пат. 124775 Україна: МПК В21С 37/04. Заявл. 23.10.2017; опубл. 25.04.2018, Бюл. № 8.

27. Ohata Yosuke. Production of composite material: пат. ЈРНО7185649 Японія: МПК В21C 23/00, В21C 23/22, В21С 25/06. Заявл. 27.12.1993; опубл. 25.07.1995.

28. Ohata Yosuke, Yamada Tsukasa, Ota Yoshinisa, Kusakai Liyunichi. Manufacture of copper or copper alloy coated steel contact wire: пат. JP11105586 (А) Япония: МПК В60М 1/13, Н01В 1/02. Заявл. 03.10.1997; опубл. 20.04.1999.

29. Ohata Yosuke, Iwayama Hiroari, Yamada Tsukasa, Tomizura Toshimizu. Trolley wire of copper- alloycoated steel, and method manufacturing the same: пат. JP2001180337 (А) Японія: МПК В21C 23/21, В21C 23/22, В60М 1/13. Заявл. 24.12.1999; опубл. 03.07.2001.

30. Федорінов В. А., Богуславський О. В., Федоринов М. В. Спосіб виготовлення армованого підвісного контактного (тролейного) дроту: пат. 132600 Україна: МПК В21С 23/22, В60М 1/13, Н01В 1/02. Заявл. 16.04.2018; опубл. 11.03.2019, Бюл. № 5.

\section{REFERENCES} (in Russian).

1. GOST 2584-86. Contact wires from copper and its alloys. Moscow: Publishing house of standards. 1986,12 p.

2. Gershman I.S., Mirchos N.V. Requirements to contact wires for high-speed railway transport. Bulletin of the Research Institute of Railway Transport. 2011, 3, p. 13. (in Russian).

3. Mochinaga I. Trends in the development of traction power supply. Railways of the world. 2002, 6, p. 20.

4. Bokov N.F. [et al.]. Organization of production of non-standard profiles of electrotechnical copper at Kamensk-Uralsky Non-Ferrous Metal Processing Plant OJSC. Production of rolled products. 2010, 8, p. 29. (in Russian).

5. Berent V.Ya. Improving the wires of the contact network. Bulletin of the Research Institute of Railway Transport. 2012. 3. P. 40-45. (in Russian).

6. Morgunov V.V., Yakubovich E.A. Production of a contact wire based on complex alloyed copper. Modern materials, equipment and technologies. 2016, 3 (4). (in Russian).

7. Slavin V.S., Norets A.I. A method of drawing a contact wire. Patent Russian Federation 2492010.October 09, 2013. (in Russian).

8. Loginov Yu.N., Mysik R.K. Semi-continuous and continuous casting of copper and its alloys in the production of contact wire. Russian caster. 2005, 1, p. 34. (in Russian).

9. Poruchikov Yu.P., Mysik R.K., Loginov Yu.N., et al. Method of metal processing with an alloying component during continuous casting. Patent USSR 1194894. November 30, 1985. (in Russian).

10. Gershman I.S., Gershman E.I. A method of manufacturing an electrical contact wire and an electrical contact wire. Patent Russian Federation 2540944. October 02, 2015. (in Russian). 
11. Berent V.Ya. Method for the manufacture of contact wires. Patent Russian Federation 2236918. September 27, 2004. (in Russian).

12. Raikov Yu.N. Economics of non-ferrous metal processing enterprises. Moscow: Intermetengineering. 2013, 336 p. (in Russian).

13. Sidelnikov S.B. Classification and fields of application of combined and combined processes for processing non-ferrous metals and alloys. University News. Non-ferrous metallurgy. 2005, 3, p. 45. (in Russian).

14. Chebotarev V.A., Samsonov A.A. Casting and rolling units for the production of wire rod, sheets and ribbons of non-ferrous metals. Heavy engineering. 2007, 5, p. 20. (in Russian).

15. Loginov Yu.N., Zuev A.Yu., Inatovich Yu.V. Analysis of high-quality rolling of oxygen-containing copper, taking into account the non-monotonicity of the hardening characteristics. Non-ferrous metals. 2012, 7, p. 77. (in Russian).

16. Loginov Yu.N., Zuev A.Yu. Form modification and deformation resistance of anisotropic continuously cast copper. Procurement in engineering. 2011, 1, p. 32. (in Russian).

17. Mysik R.K., Loginov Yu.N., Skrylnikov A.I. Contact wire. Patent Russian Federation 2261185. September 27, 2005. (in Russian).

18. Goto M., Kawakita S., Mae Y. and other. Method for producing wire for electric railways. Patent US № 5391243. Februar 21, 1995.

19. Nagasawa H., Aoki S., Kawakita S. Production of copper alloy trolley wire and hanging stringing. Patent JP № 6154838. June 03, 1994.

20. Alekhin V.L., Antropov V.N., Bushe N. A. et al. A method of manufacturing a contact wire. Patent USSR 1101323. July 07, 1984. (in Russian).

21. Berent V.Ya. A method for producing contact wires from copper-based alloys. Patent Russian Federation 2162764. Jctober 02, 2001. (in Russian).

22. Samoilenko A.K., Mochilin G.L., Rudenko V.M. and others. A method of manufacturing a contact steelaluminum wire. Patent Russian Federation 2351485. October 04, 2009. (in Russian).

23. Andreev A.V. A method of reinforcing a pendant wire. Patent Russian Federation 2195730. December 27, 2002. (in Russian).

24. Green Derek. Extrusion. Patent CA59792A Canada. Februar 29, 1872.

26. Fedorinov V.A., Gribkov E.P., Fedorinov M.V. Method of composing a dart. Patent Ukraine 124775. April 25, 2018. (in Ukrainian).

27. Ohata Yosuke. Production of composite material. Patent Japan JP HO7185649: 23/22, B21C 25/06. July $25,1995$.

28. Ohata Yosuke, Yamada Tsukasa, Ota Yoshinisa, Kusakai Liyunichi. Manufacture of copper or copper alloy coated steel contact wire. Patent Japan JP11105586 (A). April 20, 1999.

29. Ohata Yosuke, Iwayama Hiroari, Yamada Tsukasa, Tomizura Toshimizu. Trolley wire of copper- alloycoated steel, and method manufacturing the same. Patent Japan JP2001180337 (A). July 03, 2001.

30. Fedorinov V.A., Boguslavsky O.V., Fedorinov M.V. A method of manufacturing a reinforced suspended contact (trolley) wire. Patent Ukraine 132600. March 11, 2019. (in Ukrainian).

Федоринов В. А. - канд. техн. наук, проф. ДГМА;

E-mail: vladimir.fedorinov@dgma.donetsk.ua

Федоринов М. В. - канд. техн. наук, доц., ЧАО «НКМЗ»;

E-mail: michael.fedorinov@gmail.com

Кулик А. Н. - - - канд. техн. наук, доц. ДГМА;

E-mail: alexandr.kulik@dgma.donetsk.ua

Кох А. К. $\quad$ - аспирант ДГМА.

E-mail: mto@dgma.donetsk.ua

ДГМА - Донбасская государственная машиностроительная академия, г. Краматорск.

ЧАО «НКМЗ»- Частное акционерное общество «Новокраматорский машиностроительный завод», г. Краматорск. 